\title{
Role of CT in the Diagnosis and Follow up of Pediatric Oncology Patients with Fungal Infection
}

\author{
Khaled Aboualfotouh Ahmad ${ }^{1}$, Mohamed Mamdouh Mohamed', Iman Ahmed Ragab', \\ Engy Kameel Shokry ${ }^{1}$ \\ Departments of ${ }^{1}$ Radiology and ${ }^{2}$ Pediatrics, Faculty of Medicine, Ain Shams University \\ Corresponding Author: Engy Kameel Shokry, E-mail: dr.aojo@live.com, Telephone: +2 01201263105
}

\begin{abstract}
Background: invasive fungal infections are rare in pediatric population, but have a high morbidity and mortality rates despite the development of antifungal treatment. It ranges from superficial, mucosal to invasive infection.

Aim of the Work: to assess the value of $\mathrm{CT}$ in the diagnosis of invasive fungal infection and differentiating it from other causes of infection or metastatic deposits in patients with childhood cancer and persistent fever in spite of antibacterial treatment and to assess the radiological response after treatment with antifungal drugs.

Patients and Methods: our study was done over period from October 2017 to June 2018, included 22 immunocompromised pediatric patients from El -Demerdash tertiary hospital, included (8 male, and 14 female) with age range (14m- 16 yrs.). We identified immunocompromised patient of having underlying malignancy or auto-immune deficiency. We included all patients with fever, neutropenia and high CRP, in whom we suspected chest or paranasal sinus infection.

Results: in our case group; the most common underlying disease was ALL-B cell $(n=6,40 \%)$, followed by ALL-T cell $(n=2,13.3 \%)$, AML $(n=2,13.3 \%)$, aplastic $(n=3,20 \%)$, hepatobalstoma $(n=1,6.7 \%)$ and auto-immunodeficiency $(n=1,6.7 \%)$. Analysis of the radiological data showed that macronodules was the most significant finding to suggest fungal rather than bacterial infection $(53.3 \%$ vs. $0 \%$ respectively, $\mathrm{p}=0.015)$, followed by consolidation $(40 \%$ vs. $57.1 \%, \mathrm{p}=0.45)$ and ground glassing $(26.7 \%$ vs. $14.3 \%$. Cavitary lesions, pleural effusion and lung abscess were associated only with fungal disease, yet it is not considered significant enough in our study as a reliable sign to suggest fungal infection

Conclusion: increase number of hospitalized pediatric patients with fungal infection is a rising problem, with no specific criteria for early diagnosis among this population causing delay of the proper treatment. In our study hematological malignancy was the most common underlying disease with macronodules being the most specific finding to suggest fungal infection in pediatrics.
\end{abstract}

Keywords: Pediatric Oncology Patients - Fungal Infection - Candida - Aspergillus

\section{INTRODUCTION}

In the past few decades, there has been a considerable increase in the frequency of invasive fungal infection (IFI). This increase is directly related to the increased number of immunocompromised patients, due to the use of chemotherapy, immunosuppressive drugs, stem cell transplantation, and solid organ transplantation ${ }^{(\mathbf{1})}$.

The most common fungi responsible for invasive fungal infections are Candida and Aspergillus, The incidence of invasive candidiasis is higher in the pediatric age group, with the highest risk in neonates. Candida infections in older children are more similar to those in adults. In contrast, Invasive aspergillosis is rare in neonates, but occurs more frequently in older children ${ }^{(2)}$.

The most affected organs in order of frequency, are: lungs (70\%), skin (20\%), central nervous system (brain, spinal cord), and sinuses $(18 \%)^{(3)}$.

Early detection of Invasive fungal infection is of high importance, as the prognosis depends strongly on the appropriate use of antifungal early ${ }^{(4)}$.
In haemato-oncological patients, the chest $\mathrm{x}$-ray is false negative in $45-50 \%$. Therefore, the use of thin-slice chest CT $(<3 \mathrm{~mm})$ is indicated in immune -compromised patients when searching for a focus of infection ${ }^{(5)}$.

CT is not useful in acute fungal sinusitis but in a chronic stage where it can evaluate changes in the bone. In case of bone destruction, intraorbital extension, intracranial extension, or both occur rapidly, with soft tissue inflammation and abscess formation. As a result, a low dose CT scan should be adopted for repeated imaging as bone destruction can be subtle. MRI with gadolinium enhancement is better than $\mathrm{CT}$ to assess intracranial and intraorbital extension in three planes (axial, sagittal, and coronal) ${ }^{(6)}$.

\section{PATIENTS AND METHODS}

Our study was done over period from October 2017 to June 2018, included 22 immunocompromised pediatric patients from $\mathrm{El}$ - 
Demerdash tertiary hospital, included ( 8 male and 14 female) with age range (14m- 16 yrs.).

We identified immunocompromised patient of having underlying malignancy or autoimmune deficiency; hematological malignancy was found in 18 patient; 13 patient with acute lymphoid leukemia (ALL) (9 with ALL-B cell and 4 with ALL-T cell), 2 patient with acute myeloid leukemia (AML), and 3 patients with aplastic anemia.

Three patients had solid tumors (2 with hepatobalstoma, 1 with wilm's tumor) and one patient with underlying auto- immunodeficiency.

they were categorized into two groups; case group -diagnosed with invasive fungal infection based on the criteria suggested by EORTC/MSG - included 15 patients (one case was proven to have invasive candidiasis by blood culture, 2 probable cases for invasive aspergillosis by identifying the galactomannan antigen in bronchoalveolar lavage and 12 possible cases based on the host factor and a clinical criterion in absence of any mycological criteria).

The second group; control group included 7 patients diagnosed with bacterial infection and showed clinical improvement on antibiotic (one patient proved to have streptococcus as cause of infection).

We included all patients with fever and neutropenia $\quad\left(<0.5 \quad\right.$ x $10^{9} \quad$ neutrophils/L $)(<500$ neutrophils/mm3 for $>10$ days) and high CRP in whom we suspected chest or paranasal sinus infection and excluded all patient without neutropenia.

In our study not responding to empirical antibiotic was considered invasive fungal infection and empirical antifungal therapy was started.

Chest and paranasal computed tomography (CT) with contrast was performed as baseline at the beginning of episode to determine underlying fungal disease, and was followed up periodically to evaluate response to treatment.

CT scans had been obtained using GE OPTIMA 660SE MSCT 128 with $1.25-\mathrm{mm}$ collimation, Nonionic contrast medium (120-150 $\mathrm{mL}$ Optiray 320); had been injected in 22 patients via an antecubital vein at a rate of 3-4.2 $\mathrm{mL} / \mathrm{s}$ with a 12-20-s delay.

The CT scans were reviewed in a blinded fashion by an experienced pediatric chest radiologist. Pulmonary lesions were classified as macronodules (1$3 \mathrm{~cm}$ ), consolidation, ground glassing, and cavitary nodular lesion with further characterization into presence of halo sign or air crescent sign, association of pleural effusion, abscess formation and direct dissemination to nearby organs as well as paranasal sinus infection.

\section{Ethical Considerations:}

Perform only necessary CT examinations. Adjust exposure parameters for pediatric CT based on Child size: guidelines based on individual size / weight parameters should be used. Region scanned: the region of the body scanned should be limited to the smallest necessary area. Organ systems scanned: lower $\mathrm{mA}$ and/or $\mathrm{kVp}$ settings should be considered for skeletal and lung imaging. The study was approved by the Ethics Board of Ain Shams University and an informed written consent was taken from each participant in the study.

\section{Statistical Analysis}

Data were collected, revised, coded and entered to the Statistical Package for Social Science (IBM SPSS) version 23. The quantitative data were presented as mean, standard deviations and ranges when their distribution found parametric and median with inter-quartile range (IQR) when their distribution found non-parametric. Also qualitative variables were presented as number and percentages.

The comparison between groups regarding qualitative data was done by using Chi-square test.

The comparison between two independent groups with quantitative data and parametric distribution were done by using Independent t-test

The comparison between two groups with quantitative data and non-parametric distribution were done by using Mann-Whitney test.

The confidence interval was set to $95 \%$ and the margin of error accepted was set to 5\%. So, the p-value was considered significant at the level of $<0.05$.

\section{RESULTS}

Table (1): Shows comparison between patient and control group regarding age and sex

\begin{tabular}{|c|c|c|c|c|c|c|}
\hline & Control group & Patient group & \multirow[b]{2}{*}{ Test value } & \multirow[b]{2}{*}{ P-value } & \multirow[b]{2}{*}{ Sig. } \\
\hline & & No. $=7$ & No. $=15$ & & & \\
\hline Age & $\begin{array}{c}\text { Mean } \pm \text { SD } \\
\text { Range }\end{array}$ & $\begin{array}{c}5.89 \pm 4.60 \\
1.2-15\end{array}$ & $\begin{array}{c}8.55 \pm 5.03 \\
1.2-16\end{array}$ & $-1.185 \bullet$ & 0.250 & NS \\
\hline Sex & $\begin{array}{c}\text { Female } \\
\text { Male }\end{array}$ & $\begin{array}{l}4(57.1 \%) \\
3(42.9 \%)\end{array}$ & $\begin{array}{c}10(66.7 \%) \\
5(33.3 \%)\end{array}$ & $0.187^{*}$ & 0.665 & NS \\
\hline
\end{tabular}

*: Chi-square test; $\bullet$ : Independent t-test

NS: Non significant; S: Significant; HS: Highly significant

P-value $>0.05$ Non significant

$\mathrm{P}$-value $<0.05$ Significant

$\mathrm{P}$-value $<0.01$ Highly significant 
Table (1) shows no statically significant difference regarding age and sex.

Table (2): Shows the frequency of underlying malignancy and immunodeficiency in both groups

\begin{tabular}{|c|c|c|c|c|c|c|c|}
\hline \multirow[t]{2}{*}{ Diagnosis } & \multicolumn{2}{|c|}{$\begin{array}{c}\text { Control } \\
\text { group }\end{array}$} & \multicolumn{2}{|c|}{$\begin{array}{c}\text { Patient } \\
\text { group }\end{array}$} & \multirow{2}{*}{$\begin{array}{c}\text { Test } \\
\text { value* }\end{array}$} & \multirow{2}{*}{ P-value } & \multirow[t]{2}{*}{ Sig } \\
\hline & No. & $\%$ & No. & $\%$ & & & \\
\hline \multicolumn{5}{|c|}{ Hematological malignancy; } & \multirow{9}{*}{5.867} & & \\
\hline \begin{tabular}{|ll}
$1-$ & ALL $-\mathrm{B}$ cell \\
\end{tabular} & 3 & $42.9 \%$ & \begin{tabular}{l|l}
6 & 2 \\
\end{tabular} & $40.0 \%$ & & \multirow{8}{*}{0.438} & \multirow{8}{*}{ NS } \\
\hline 2- $\quad$ ALL $-\mathrm{T}$ cell & 2 & $28.6 \%$ & 2 & $13.3 \%$ & & & \\
\hline 3- $\quad$ AML & 0 & $0.0 \%$ & 2 & $13.3 \%$ & & & \\
\hline 4- $\quad$ Aplastic & 0 & $0.0 \%$ & 3 & $20.0 \%$ & & & \\
\hline \multicolumn{5}{|l|}{ Solid tumors; } & & & \\
\hline 5- Hepatobalstoma & 1 & $14.3 \%$ & 1 & $6.7 \%$ & & & \\
\hline 6- Wilm's & 1 & $14.3 \%$ & 0 & $0.0 \%$ & & & \\
\hline Auto Immunodeficiency & 0 & $0.0 \%$ & 1 & $6.7 \%$ & & & \\
\hline
\end{tabular}

In table (2) there was no significant difference in both groups.

Table (3): Shows the clinical picture and the laboratory finding in both groups at the time of infection

\begin{tabular}{|c|c|c|c|c|c|c|}
\hline & \begin{tabular}{|l|} 
Control group \\
\end{tabular} & \begin{tabular}{|l|} 
Patient group \\
\end{tabular} & \multirow{2}{*}{ Test value } & \multirow{2}{*}{ P-value } & \multirow{2}{*}{ Sig. } \\
\hline & & \begin{tabular}{|l|} 
No. $=7$ \\
\end{tabular} & No. $=15$ & & & \\
\hline Fever & $\begin{array}{l}\text { Negative } \\
\text { Positive }\end{array}$ & $\begin{array}{c}0(0.0 \%) \\
700 \%)\end{array}$ & $\begin{array}{c}0(0.0 \%) \\
15(00 . \%)\end{array}$ & NA & NA & - \\
\hline TLC (4.5-13.5) & $\begin{array}{l}\text { Median (IQR) } \\
\text { Range }\end{array}$ & $\begin{array}{c}1.1(0.6-2.5) \\
0.4-4.7\end{array}$ & $\begin{array}{c}2.4(0.6-3.9) \\
0.4-10.4\end{array}$ & $-0.565 \neq$ & 0.572 & NS \\
\hline Neutrophilis (2-8) & $\begin{array}{l}\text { Median (IQR) } \\
\text { Range }\end{array}$ & $\begin{array}{c}0.1(0.09-0.4) \\
0.03-1.4\end{array}$ & $\begin{array}{c}0.43(0.1-1.76) \\
0.05-3.3\end{array}$ & $-1.482 \neq$ & 0.138 & NS \\
\hline CRP(less 6) & $\begin{array}{l}\text { Median (IQR) } \\
\text { Range }\end{array}$ & $\begin{array}{c}35(6-48) \\
6-48\end{array}$ & $\begin{array}{c}48(24-96) \\
12-200\end{array}$ & $-0.929 \neq$ & 0.353 & NS \\
\hline
\end{tabular}

*: Chi-square test; $\bullet$ : Independent t-test; $\neq$ : Mann-Whitney test

NS: Non significant; S: Significant; HS: Highly significant

In table (3) all the patients in both groups had fever more than $38^{\circ}$ and neutropenia $(<500$ neutrophils/mm3 for $>10$ days) with high CRP.

Table (4): Shows the frequency of CT chest imaging findings in both groups.

\begin{tabular}{|c|c|c|c|c|c|c|c|c|}
\hline & & \multicolumn{2}{|c|}{ Control group } & \multicolumn{2}{|c|}{ Patient group } & \multirow{2}{*}{ Test value* } & \multirow{2}{*}{ P-value } & \multirow[b]{2}{*}{ Sig. } \\
\hline & & No. & $\%$ & No. & $\%$ & & & \\
\hline \multirow{2}{*}{ Macronodules } & Negative & 7 & $100.0 \%$ & 7 & $46.7 \%$ & \multirow{2}{*}{5.867} & \multirow{2}{*}{0.015} & \multirow{2}{*}{$\mathrm{s}$} \\
\hline & \begin{tabular}{|l|} 
Positive \\
\end{tabular} & 0 & $0.0 \%$ & 8 & $53.3 \%$ & & & \\
\hline \multirow{2}{*}{ Cavitary lesion } & Negative & 7 & $100.0 \%$ & 12 & $80.0 \%$ & \multirow{2}{*}{1.621} & \multirow{2}{*}{0.203} & \multirow{2}{*}{ NS } \\
\hline & Positive & 0 & $0.0 \%$ & 3 & $20.0 \%$ & & & \\
\hline \multirow{2}{*}{ Halo sign } & Negative & 7 & $100.0 \%$ & 15 & $100.0 \%$ & \multirow{2}{*}{ NA } & \multirow{2}{*}{ NA } & \multirow{2}{*}{ - } \\
\hline & \begin{tabular}{|l|} 
Positive \\
\end{tabular} & 0 & $0.0 \%$ & 0 & $0.0 \%$ & & & \\
\hline \multirow{2}{*}{ Air crescent sign } & Negative & 7 & $100.0 \%$ & 15 & $100.0 \%$ & \multirow{2}{*}{ NA } & \multirow{2}{*}{ NA } & \multirow{2}{*}{ - } \\
\hline & \begin{tabular}{|l|} 
Positive \\
\end{tabular} & 0 & $0.0 \%$ & 0 & $0.0 \%$ & & & \\
\hline \multirow{2}{*}{ Consolidation } & Negative & 3 & $42.9 \%$ & 9 & $60.0 \%$ & \multirow{2}{*}{0.566} & \multirow{2}{*}{0.452} & \multirow{2}{*}{ NS } \\
\hline & \begin{tabular}{|l|} 
Positive \\
\end{tabular} & 4 & $57.1 \%$ & 6 & $40.0 \%$ & & & \\
\hline \multirow{2}{*}{ Pleural effusion } & Negative & 7 & $100.0 \%$ & 12 & $80.0 \%$ & \multirow{2}{*}{1.621} & \multirow{2}{*}{0.203} & \multirow{2}{*}{ NS } \\
\hline & \begin{tabular}{|l|} 
Positive \\
\end{tabular} & 0 & $0.0 \%$ & 3 & $20.0 \%$ & & & \\
\hline \multirow{2}{*}{ Ground glassing } & Negative & 6 & $85.7 \%$ & 11 & $73.3 \%$ & \multirow{2}{*}{0.417} & \multirow{2}{*}{0.519} & \multirow{2}{*}{ NS } \\
\hline & \begin{tabular}{|l|} 
Positive \\
\end{tabular} & 1 & $14.3 \%$ & 4 & $26.7 \%$ & & & \\
\hline \multirow{2}{*}{ Lung abscess } & Negative & 7 & $100.0 \%$ & 14 & $93.3 \%$ & \multirow{2}{*}{0.489} & \multirow{2}{*}{0.484} & \\
\hline & \begin{tabular}{|l|} 
Positive \\
\end{tabular} & 0 & $0.0 \%$ & 1 & $6.7 \%$ & & & NS \\
\hline
\end{tabular}

The most significant findings were the presence of macronodules in patient group (53.5\%) compared to control group (0.0\%).

Table (5): Shows the frequency of associated sinusitis/fungal sinusitis and complication in both groups with underlying treatment in both groups

\begin{tabular}{|c|c|c|c|c|c|c|c|c|}
\hline & \multicolumn{2}{|c|}{ Control group } & \multicolumn{2}{|c|}{ Patient group } & \multirow{2}{*}{ Test value* } & \multirow{2}{*}{ P-value } & \multirow{2}{*}{ Sig. } \\
\hline & & No. & $\%$ & No. & $\%$ & & & \\
\hline \multirow{3}{*}{ Sinusitis } & Negative & 4 & $57.1 \%$ & 6 & $40.0 \%$ & \multirow{3}{*}{0.880} & \multirow{3}{*}{0.644} & \multirow{3}{*}{ NS } \\
\hline & Sinusitis & 3 & $42.9 \%$ & 8 & $53.3 \%$ & & & \\
\hline & Fungal sinusitis & 0 & $0.0 \%$ & 1 & $6.7 \%$ & & & \\
\hline Liver & $\begin{array}{l}\text { Negative } \\
\text { Positive }\end{array}$ & 7 & $100.0 \%$ & 14 & $\begin{array}{l}93.3 \% \\
6.7 \%\end{array}$ & 0.489 & 0.484 & NS \\
\hline \multirow{2}{*}{ Treatment } & Antifungal & 0 & $0.0 \%$ & 15 & $100.0 \%$ & \multirow{2}{*}{22.000} & \multirow{2}{*}{0.000} & \multirow{2}{*}{ HS } \\
\hline & Antibiotic & 7 & $100.0 \%$ & 0 & $0.0 \%$ & & & \\
\hline
\end{tabular}

*: Chi-square test; $\bullet$ : Independent t-test

NS: Non significant; S: Significant; HS: Highly significant

Table (5) shows that in the patient group; 8 patients $(53.3 \%)$ had chest manifestation with sinusitis, and only one patient $(6.7 \%)$ had invasive fungal sinusitis without chest manifestation.

And in the control group From 7 patients treated for bacterial infection; 3 patients $(42.9 \%)$ had sinusitis only.

Only one patient $(6.7 \%)$ had liver abscess that seen extending from right lower lung lobe through right hemidiaphragm.

Table (6): Shows the overall prognosis of both patient and control group

\begin{tabular}{|c|c|c|c|c|c|c|c|}
\hline \multirow{2}{*}{ Prognosis } & \multicolumn{9}{|c|}{ Control group } & \multicolumn{2}{|c|}{ Patient group } & \multirow{2}{*}{ Test value** } & \multirow{2}{*}{ P-value } & \multirow{2}{*}{ Sig. } \\
\cline { 2 - 5 } & No. & $\%$ & No. & \% & & & \\
\hline Improved & 5 & $71.4 \%$ & 11 & $73.3 \%$ & & & \\
\hline Progressive & 0 & $0.0 \%$ & 2 & $13.3 \%$ & \multirow{2}{*}{1.545} & 0.462 & NS \\
\hline Died & 2 & $28.6 \%$ & 2 & $13.3 \%$ & & & \\
\hline
\end{tabular}

*: Chi-square test; $\bullet$ : Independent t-test

NS: Non significant; S: Significant; HS: Highly significant

In table (6) the overall mortality rate was the same in both groups.

\section{DISCUSSION}

Invasive fungal infection is a major cause of morbidity and mortality causing a huge health care burden. Its incidence has increased in the past few decades due to the growth of the immunocompromised population such as patient with underlying malignancy, HIV, who underwent bone marrow or solid organ transplantation or treated with corticosteroid over long durations, radiotherapy, and chemotherapy ${ }^{(7)}$.

The candida and Aspergillus considered the most common cause of infection ${ }^{(8)}$. 
Studies proved that better outcome is associated with early diagnosis and treatment. The diagnosis of invasive fungal infection is challenging with even less studies available for pediatric population ${ }^{(9)}$.

The EORTC/MSG criteria require direct tissue specimen to diagnose proven fungal infection, however it's particularly difficult to obtain in most cases due to the underlying thrombocytopenia and high risk of bleeding complication.

Blood cultures has a low sensitivity reaches up to $50-70 \%$ also it consider the gold standard in diagnosis of candidiasis and some studies recommended repeating the culture from three different sites to optimize the diagnosis, and CSF sample normal in almost have the cases culture -proved candida meningitis ${ }^{(\mathbf{1 0})}$.

New techniques using ELISA for detection of galactomannan and $\beta$-D-glucans had been developed. Galactomannan has high sensitivity and specificity also many factors cause false positive or false negative results and repeating testing is associated with less false positive results, $\beta$-Dglucans has not received widespread acceptance due to difficulties in performance techniques and lack of specificity ${ }^{(\mathbf{1 1}, \mathbf{1 2})}$.

Molecular method such as PCR is used to detect fungal DNA in different types of specimens, including whole blood, serum, plasma, bronchoalveolar lavage, CSF and biopsy tissue from different sites. Yet it is still not widely used due to the lack of standardization, expensive and can lead to false positive results if the sample becomes contaminated as well as the difficulty in extracting intact fungal DNA.

CT scan is widely used as screening method when fungal infection is suspected with studies show better prognosis with initiation of treatment with early CT findings such as halo sign in chest CT.

The halo sign and air crescent sign is two key image findings in HRCT in adults followed by cavitation, macronodules and consolidation. Unlike in pediatric population the halo sign and air crescent sign is rare.

We revise the data obtained from 22 immunocompromised pediatric patients from ELDemerdash Hospital over period from October 2017 to June 2018, with underlying malignancy or immunodeficiency who developed fever and neutropenia $(<500$ neutrophils/mm3) with high
CRP, they were categorized into two groups; case group -diagnosed with invasive fungal infectionbased on the criteria suggested by EORTC/MSG in 2002 and revised at 2008 our study, it included 15 patients (one case was proven to have invasive candidiasis by blood culture, 2 probable cases for invasive aspergillosis by identifying the galactomannan antigen in bronchoalveolar lavage and 12 possible cases based on the host factor and a clinical criterion in absence of any mycological criteria).

The two groups had the same general characteristics with no significant differences based on the chi-square test in term of age $(\mathrm{t}=-1.18$, mean for case group $8.55 \pm 5.03$, mean for control group5.89+4.60), sex $(\mathrm{t}=0.187)$, and all patients in both groups had fever $(100 \%)$, neutropenia $(100 \%$, $\mathrm{p}=0.13)$ and high CRP $(\mathrm{p}=0.35)$.

In our patients group; the most common underlying disease was ALL-B cell ( $\mathrm{n}=6,40 \%$ with), followed by ALL-T cell $(n=2,13.3 \%)$, AML $(n=2$, $13.3 \%)$, aplastic $(\mathrm{n}=3,20 \%)$, hepatobalstoma $(\mathrm{n}=1$, $6.7 \%)$ and auto-immunodeficiency $(\mathrm{n}=1,6.7 \%)$

From 15 patients; 14 patients diagnosed with invasive pulmonary infection, and only 1 patient diagnosed with invasive fungal sinusitis.

These was also common in a retrospective study included 66 pediatric patients over 43 year period; in which ALL was found in 29 patient, AML in 26 patient, and aplastic was the underlying malignancy in 2 patients only. And the most common site of infection was the lung $(n=46$, $70 \%$ ), followed by invasive sinus infection in $(\mathrm{n}=12,18 \%)$. With $(\mathrm{n}=52,78 \%)$ had neutropenia before onset of the disease ${ }^{(13)}$.

Unlike another retrospective study included 1047 pediatric patients from a tertiary medical center over the period from1998-2006; the AML was the most common underlying disease ( $\mathrm{n}$ $=26,34.7 \%)$ followed by ALL $(\mathrm{n}=24,32 \%)^{(14)}$.

In a 5-year observational study; hematological malignancies accounted for $6.8 \%(n=13$ of 189). And the lung was the primary site in 12 cases ${ }^{(15)}$.

Analysis of the radiological data; in the patients group the most common findings was macronodules, in comparison to the control group the presence of macronodules was the most significant finding to suggest fungal rather than bacterial infection (53.3\% vs. $0 \%$ respectively, $\mathrm{p}=0.015$ ), followed by consolidation 
which was considered to be the main radiological finding in the control group ( $40 \%$ vs. $57.1 \%, \mathrm{p}=0.45$ ), ground glassing (26.7\% vs. $14.3 \%$.

Cavitary lesions, pleural effusion and lung abscess were associated only with fungal disease, yet it is not considered significant enough in our study as a reliable sign to suggest fungal infection.

This findings goes with Greene et al. (16) study included 235 patients, with the macronodules was the most common finding (94\%), and consolidation (30\%), unlike our study it had high percentage of halo sign reaching up to (61\%), but it included older age group (12-70 years) which may explain the higher incidence of halo sign.

Similar data confirmed by Souza et al. ${ }^{(17)}$, which concluded that both candida and Aspergillus most common chest finding was macronodules reaching (95\%.84\% respectively).

And in Franquet et al. ${ }^{(18)}$ retrospective study which included 17 patient with proven pulmonary candidiasis, nodules were the most common finding (88\%), followed by consolidation in (65\%).

In another retrospective study included 139 pediatric patients from 6 medical centers; the most frequent diagnostic radiologic finding was nodules (34.6\%), followed by cavitation in (24.5\%). Only ( $2.2 \%)$ of children showed the air crescent sign, (11\%) demonstrated the halo sign, which goes with our findings and confirms the low incidence of the halo sign and air crescent sign in pediatric population ${ }^{(19)}$.

Complication was rare in our study, as only one patient $(6.7 \%)$ developed lung abscess with right hemi-diaphragm and liver invasion.

It was also a rare finding in 13 month period study included 86 pediatric patients with underlying hematological disease as only 2 cases had liver abscess ${ }^{(9)}$.

There was no significant difference in the overall mortality rate in case group compared to in control group (13.3\% vs. $28.6 \%$ respectively).

The incidence were higher in other studies; in Abbasi et al. ${ }^{(13)}$ study the mortality rate was $85 \%$ in the first year after the initial diagnosis, in Badiee et al. ${ }^{(9)}$ study the mortality rate was up to $50 \%$, and in Ansari et al. ${ }^{(20)}$ study the mortality rate was $61.5 \%$ with invasive aspergillosis.
The difference in the results may be contributed to the small sample size and the small number of control group.

\section{CONCLUSION}

Increase number of hospitalized pediatric patients with fungal infection is a rising problem, with no specific criteria for early diagnosis among this population causing delay of the proper treatment. In our study hematological malignancy was the most common underlying disease with macronodules being the most specific finding to suggest fungal infection in pediatrics.

\section{REFERENCES}

1. Alfred OA, Mike MS, Rudi AJ et al. (2016): Imaging fungal infections in children. Clin Transl Imaging, 4: 57-622.

2. Olivier B, Julie G, Jerome H et al. (2012): Invasive fungal disease in PICU: epidemiology and risk factors. Annals of Intensive Care, 2: 6-14.

3. Arturo VH, David PP, Liliana HG et al. (2013): Pulmonary aspergillus in pediatric patient by $\mathrm{Ct}$ aspergilosis. Rev Colomb Radiol., 24(2): 3692-7.

4. Georgiadou SP, Sipsas NV, Marom EM et al. (2011): The diagnostic value of halo and reversed halo signs for invasive mold infections in compromised hosts. Clinical Infectious Diseases, 52(9): 1144-55.

5. Gompelmann D, Heussel CP, Schuhmann M et al. (2011): The role of diagnostic imaging in the management of invasive fungal diseases-report from an interactive workshop. Mycoses, 54: 27-31.

6. Schelenz S, Barnes RA, Barton RC et al. (2015): British Society for Medical Mycology best practice recommendations for the diagnosis of serious fungal diseases. The Lancet Infectious Diseases, 15(4): 461-74.

7. Garey KW, Rege M, Pai MP et al. (2006): Time to initiation of fluconazole therapy impacts mortality in patients with candidemia: a multi-institutional study. Clin Infect Dis., 43(1): 25-31.

8. Ankrah AO, Sathekge MM, Dierckx RA et al. (2016): Imaging fungal infections in children. Clin Transl Imaging, 4: 57. 
9. Badiee P, Zareifar S, Haddadi P et al. (2017): Incidence of Fungal Infections in Pediatric Patients with Hematologic Neoplasms. Arch Pediatr Infect Dis., 5(3): e41317.

10. Calley JL and Warris A (2017): Recognition and diagnosis of invasive fungal infections in neonates. Journal of Infection, 74: S108-S113.

11. Riwes MM and Wingard JR (2012): Diagnostic methods for invasive fungal diseases in patients with hematologic malignancies. Expert Rev Hematol., 5(6): 661-669.

12. Flörl L (2017): Current Challenges in the Diagnosis of Fungal Infections. Methods Mol Biol., 1508: 3-15.

13. Abbasi S, Shenep JL, Hughes WT et al. (1999): Aspergillosis in children with cancer: A 34-year experience. Clin Infect Dis., 29(5): 1210-9.

14. Mor M1, Gilad G, Kornreich L et al. (2011): Invasive fungal infections in pediatric oncology. Pediatr Blood Cancer, 56(7): 1092-7.

15. Groll AH, Kurz M, Schneider $W$ et al. (1999): Five-year-survey of invasive aspergillosis in a paediatric cancer centre. Epidemiology, management and long-term survival. Mycoses, 42(7-8): 431-42.
16. Greene RE, Schlamm HT, Oestmann JW et al. (2007): Imaging findings in acute invasive pulmonary aspergillosis: clinical significance of the halo sign. Clin Infect Dis., 44(3): 373-9.

17. Souza CA, Müller NL, Marchiori E et al. (2006): Pulmonary invasive aspergillosis and candidiasis in immunocompromised patients: a comparative study of the high-resolution CT findings. Journal of Thoracic Imaging, 21(3): 184-9.

18. Franquet T, Müller NL, Lee KS et al. (2005): Pulmonary candidiasis after hematopoietic stem cell transplantation: thin-section CT findings. Radiology, 236(1): 332-7.

19. Burgos A, Zaoutis TE, Dvorak CC et al. (2008): Pediatric invasive aspergillosis: a multicenter retrospective analysis of 139 contemporary cases. Pediatrics, 121(5): e1286-94.

20. Ansari S, Kiumarsi A, Rostami $T$ et al. (2014): Fungal Infections in Pediatric Patients with Hematologic Malignancies. Iranian Journal of Blood and Cancer, 6(4): 213-4. 